\title{
Induced pluripotent stem cell: A headway in reprogramming with promising approach in regenerative biology
}

\author{
N. Rawat and M. K. Singh \\ Embryo Biotechnology Lab, Animal Biotechnology Centre, ICAR - National Dairy Research Institute, Karnal - 132001 , \\ Haryana, India. \\ Corresponding author: M. K. Singh, e-mail: drmanojvet@gmail.com \\ Co-author: NR: rawatnidhi1990@gmail.com \\ Received: 04-02-2017, Accepted: 26-04-2017, Published online: 14-06-2017
}

doi: 10.14202/vetworld.2017.640-649 How to cite this article: Rawat N, Singh MK (2017) Induced pluripotent stem cell: A headway in reprogramming with promising approach in regenerative biology, Veterinary World, 10(6): 640-649.

\begin{abstract}
Since the embryonic stem cells have knocked the doorsteps, they have proved themselves in the field of science, research, and medicines, but the hovered restrictions confine their application in human welfare. Alternate approaches used to reprogram the cells to the pluripotent state were not up to par, but the innovation of induced pluripotent stem cells (iPSCs) paved a new hope for the researchers. Soon after the discovery, iPSCs technology is undergoing renaissance day by day, i.e., from the use of genetic material to recombinant proteins and now only chemicals are employed to convert somatic cells to iPSCs. Thus, this technique is moving straightforward and productive at an astonishing pace. Here, we provide a brief introduction to iPSCs, the mechanism and methods for their generation, their prevailing and prospective applications and the future opportunities that can be expected from them.
\end{abstract}

Keywords: cellular reprogramming, embryonic stem cells, induced pluripotent stem cells, stem cells.

\section{Introduction}

Stem cells are the special primal cells which retain two peculiar properties: Self-renewal to persist their undifferentiated state and differentiation potential to give rise to specialized cell types. On the basis of differentiation ability, they are categorized as totipotent, pluripotent, and multipotent stem cells. On the basis of origin, they can be categorized as embryonic stem cells (ESCs), derived from inner cell mass cells of blastocysts, and can differentiate into all the derivatives of three primary germ layers. The other cell types are adult stem cells, present in adult tissues. These are multipotent cells which are lineage specific and produce a limited number of cell types [1]. The ESCs possess all the qualities required for their contribution in scientific research and medicinal purposes, but they have limitations as immunologic rejection, and raising ethical and moral concerns because generation of ESCs requires the destruction of embryos [2]. To overcome these drawbacks, attempts have been taken to achieve individual-specific pluripotent stem cells by somatic cell nuclear transfer [3], treatment with an extract of pluripotent cells [4] and cell fusion [5]. All these approaches of nuclear reprogramming are accompanied by frailties as a technical inconvenience, partial reprogramming, and tetraploid formation, respectively, which hamper their use in medical science and technology [6].

Copyright: Rawat and Singh. Open Access. This article is distributed under the terms of the Creative Commons Attribution 4.0 International License (http://creativecommons.org/licenses/ by/4.0/), which permits unrestricted use, distribution, and reproduction in any medium, provided you give appropriate credit to the original author(s) and the source, provide a link to the Creative Commons license, and indicate if changes were made. The Creative Commons Public Domain Dedication waiver (http:// creativecommons.org/publicdomain/zero/1.0/) applies to the data made available in this article, unless otherwise stated.
To address these shortcomings, Takahashi and Yamanaka in 2006 [6] introduced an advanced step toward nuclear reprogramming based on transcription factor action for generation of new stem cell type called "induced pluripotent stem cells (iPSCs)." They tried 24 candidate factors for their ability to induce pluripotency and concluded that four fundamental transcription factors Oct-3/4, Sox2, c-Myc, and Klf4 (also called Yamanaka factors) are vital for conversion of mouse fibroblasts into pluripotent stem cells. This innovative discovery has changed the view about development and cellular specialization and hence rewarded by the Nobel Prize in 2012.

\section{Comparison between iPS and ES Cells}

iPSCs share many similarities with ESCs in terms of their morphology, surface markers expression, feeder dependence, and in vivo teratoma formation capacity. The in vitro differentiation potential of iPSCs is distinctive as compared to ESCs. Furthermore, the DNA methylation pattern between iPSCs and ESCs has revealed certain differentially methylated regions. Thus, the epigenetic status of iPSCs partially differs from ESCs which may be due to the epigenetic memory of the cell type from where it is originated [7] (Table-1).

The iPSCs and ESCs are categorized into two states-naive and prime; distinguished by morphology, gene expression pattern, and external signal dependence. Naive state cells are conventionally mouse-type ES/iPSCs, which form compact domeshaped colonies and proliferate very rapidly. They are dependent on external LIF signals for their growth and proliferation. On the contrary, prime state cells are human type ES/iPSCs, which form flat colonies 
Table-1: Comparison between iPSCs and ESCs.

\begin{tabular}{|c|c|c|}
\hline Features & iPSCs & ESCs \\
\hline Source of generation & Somatic cells & Embryos \\
\hline Ease of generation & $\begin{array}{l}\text { Technically } \\
\text { straightforward }\end{array}$ & Expertise required \\
\hline Nature of cells & Pluripotent & Pluripotent \\
\hline Teratoma formation & Yes & Yes \\
\hline Self-renewal capacity & Yes & Yes \\
\hline Pre-mature aging & Yes & No \\
\hline Telomerase activity & High & High \\
\hline Immuno-rejection & No & Yes \\
\hline Abnormalities in cells & High & Low \\
\hline Clinical applications & Widely used & Restricted \\
\hline Ethical concerns & No & Yes \\
\hline
\end{tabular}

iPSCs=Induced pluripotent stem cells, ESCs=Embryonic stem cells

and dependent on the basic fibroblast growth factor (bFGF) signal for their proliferation [8]. They proliferate very slowly as compared to naive state cells. They are also called epiblast stem cells (EpiSCs). The EpiSCs have the potential to differentiate into various cell types but could not form chimeric mice when injected into blastocyst. This represents the difference of their developmental stage in comparison to naive state cells. This developmental hurdle can be recovered by the introduction of pluripotent genes which can convert their status to mouse ES-like cells [9].

\section{Mechanism of Path Switching}

\section{How the process starts}

The first noticeable change that takes place during the reprogramming of fibroblasts is mesenchymal-epithelial transition (MET), reversal of epithelial-mesenchymal transition (EMT), which occurs during early gastrulation. The two main genes involved in switching of EMT and MET states are E-cadherin and Snail. Upregulation of E-cadherin is crucial for initiating MET process, and upregulation of Snail is responsible for gene reorganization during EMT. E-cadherin is a transmembrane constituent of intercellular adherens junctions responsible for maintaining epithelial cohesion. The snail is a basic helix-loop-helix transcription factor that binds to specific sequences called E-boxes and represses the transcription of E-cadherin and other key epithelial regulators [10]. Thus, the exogenous reprogramming factors inhibit the key mesenchymal genes and trigger an epithelial program to overcome the EMT epigenetic barrier of fibroblasts for inducing the state of pluripotency in them.

\section{The regulatory pathways involved}

The extrinsic stimuli and intrinsic circuitries play a synergistic role in sustaining the undifferentiated and self-renewing state of cells. The influential factors involved in maintaining pluripotency are leukemia inhibitory factor (LIF), transforming growth factors (TGFs), and FGFs. LIF is a member of the interleukin-6 cytokines. It is a key factor in maintaining pluripotency by inhibiting differentiation. On LIF

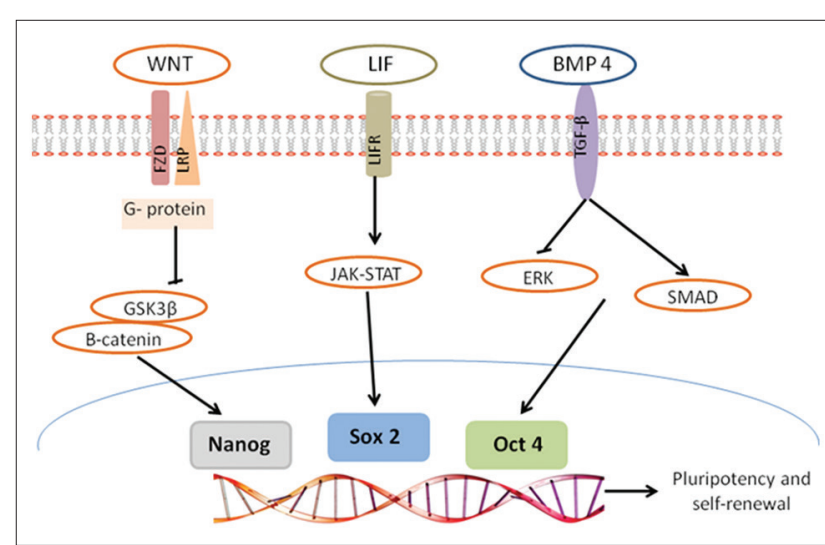

Figure-1: Signaling pathways and transcription factors regulates cell stemness.

binding to the receptor, JAK-STAT pathways becomes activated. STAT3 self phosphorylates themselves to forms a homodimer, which translocates to the nucleus, where it binds to gene enhancers and regulates target gene expression. Thus, the LIF/JAK/STAT3 pathway maintains pluripotency [11] (Figure-1).

Another pathway involved in the maintenance of pluripotency is TGF- $\beta$ superfamily which includes TGF- $\beta$, activin, inhibin, growth differentiation factor, bone morphogenetic proteins, etc. The TGF- $\beta$ members follow signaling pathway by binding to heteromeric complexes of serine/threonine kinase receptors, which subsequently activate intracellular Smad proteins. Thus, TGF- $\beta$-related signaling pathways are crucially involved in regulating the pluripotency and cell fate of ESCs [12]. FGF signaling also plays a decisive role in maintaining ESCs pluripotency. In consistence, withdrawal of FGFs or interference of FGF signaling by FGF receptor (FGFR) inhibitors causes cellular differentiation. FGFs signaling begins by binding to FGFRs which further triggers diverse signaling cascades, including MAPKs pathway, JAK/STAT pathway, PI3K pathway, and PLC pathway. Furthermore, FGF2 helps in maintaining the cells in their undifferentiated state by inducing the feeder layer cells to secrete TGF- $\beta 1$ and insulin-like growth factor 2 [13].

The primary role of the reprogramming factors at the early phase is to reverse the EMT process and to initiate MET. TGF- $\beta$ signaling pathway is the primary target of the reprogramming factors: Tgf $\beta 1$ and Tgf $\beta 3$, two members of TGF- $\beta$ superfamily, are repressed by c-Myc and Oct $4 / \mathrm{Klf} 4$, respectively, Tgf $\beta R 2$ is suppressed by c-Myc, Tgf $\beta R 3$ is suppressed by Oct $4 / \operatorname{Sox} 2$. The silencing of TGF- $\beta$ signaling leads to the inhibition of expression of Snail, which is critical for EMT. Klf4 activates E-cadherin and other epithelial program to start MET. Thus, there is the peculiar distribution of task among the transcription factors for reprogramming the fibroblast cells to pluripotent state $[14,15]$.

\section{Methods of Generation of iPSCs}

Direct reprogramming of somatic cells by introducing a set of known genes to revert them to 
embryonic state is a very promising approach. This technique involves retroviral and lentiviral vectors with strong promoters for higher efficiency which integrate their genome into the host chromosome. The other class of vectors are non-integrating type which includes viral as well as non-viral vectors. Alternative method to generate iPSCs is substitution of genetic factors with small molecules which alters the regulatory pathways and epigenetic state of the cells.

\section{Integrating method}

The pioneers of this technique, Yamanaka and Takahashi had used retroviral-mediated transduction of four set of genes (Oct4, Sox2, c-Myc, and Klf4) to re-programme mouse fibroblasts and induces them to ESC like state [16]. Therefore, majority of studies have used integrating types of vector for delivery of transcription factors as they are powerful tools to introduce foreign genes into host chromosomes and hence results in higher efficiency (Table-2) [16-26]. However, they are followed by many challenges for their use in therapeutic purposes. The primary drawback of genome-integrating vectors is potential risks of random and permanent integration of virus into the host genome at multiple sites which can result in insertional mutations and even in tumorigenesis. Thus, efficiency and safety are the two major issues involved in clinical applications of iPSCs. Recently, several approaches have been developed to generate safer transgene- or integration-free iPSCs.

Lentiviral vectors are another type of integrating vectors which can infect cells that are not actively dividing, unlike retroviral vectors which can infect only dividing cells to efficiently produce iPSCs (Table-3) [27-31].

\section{Non-integrating methods}

For generating transgene-free or integration-free iPSCs, a series of non-integrating vectors have been employed which includes viral as well as non-viral vectors. Some of them are discussed below.

\section{Viral methods}

\section{Adenoviral transduction}

Adenoviruses are among the most commonly used vectors next to retroviruses. The virus undergoes receptor-mediated endocytosis, then released in the cytosol and reaches the nucleus for carrying out viral replication and transcription. The translation of the transcripted mRNA occurs within $18 \mathrm{~h}$ after infection, and hence, the transgene is expressed with the maximum level at $48-72 \mathrm{~h}$ post transduction $[32,33]$. They manifested high transduction efficiency for cells in quiescent as well as dividing phase and shows high levels of short-term expression.

\section{Sendai virus transduction}

Unlike other RNA viruses, Sendai virus escapes the route to the nucleus and replicates in the cytoplasm of infected cells. Thus, it cannot integrate into the host genome and allows expression of transgenes without risk of modification of host genome. Hence, the iPSCs generated are genetically intact and carries the same genome DNA as the original cells [34]. In addition, Sendai virus vector is capable to infect a vast host range and are non-pathogenic to humans. Among viral vectors, it has been considered a quintessential tool for cell reprogramming and stem cell research [35].

\section{Non-viral methods}

DNA vectors are more stable than viruses and can be conveniently thawed and re-frozen through several usages. The non-viral vectors recently developed for reprogramming are.

Episomal plasmid

Episomal plasmids are based on the EpsteinBarr nuclear antigen-1 (oriP/EBNA-1). They anchor

Table-2: Generation of iPSCs using retroviral vectors.

\begin{tabular}{lllr}
\hline Species & Cell type & Genes introduced & References \\
\hline Mouse & Embryonic fibroblasts & Oct4, Sox2, Nanog, KIf4, c-Myc & {$[16]$} \\
Mouse & Embryonic and adult fibroblasts & Oct4, Sox2, KIf4, C-Myc & {$[17,18]$} \\
Mouse & Cochlear cells & Oct4, Sox2, KIf4 & {$[19]$} \\
Canine & Adult fibroblast & Oct4, Sox2, KIf4, c-Myc & {$[20]$} \\
Porcine & Embryonic fibroblast & Oct4, Sox2, KIf4, C-Myc & {$[21,22]$} \\
Bovine & Embryonic fibroblasts & Oct4, Sox2, Nanog, KIf4, c-Myc, Lin22 & {$[23]$} \\
Buffalo & Fetal fibroblasts & Oct4, Sox2, KIf4, c-Myc & {$[24]$} \\
Human & Adult fibroblasts & Oct4, Sox2, Klf4, C-Myc & {$[25,26]$} \\
\hline
\end{tabular}

iPSCs=Induced pluripotent stem cells

Table-3: Generation of iPSCs using lentiviral vectors.

\begin{tabular}{llll}
\hline Species & Cell type & Genes transduced & References \\
\hline Rat & Adult fibroblasts & Oct4, Sox2, KIf4, c-Myc & {$[27]$} \\
Rabbit & Adult somatic cells & Oct4, Sox2, KIf4, c-Myc & [28] \\
Goat & Ear fibroblasts & Oct4, Sox2, KIf4, c-Myc, nanog, Lin28, SV40 large & {$[29]$} \\
& T antigen, hTERT & {$[30]$} \\
Bovine & Fetal fibroblast & Oct4, Sox2, KIf4, c-Myc & {$[31]$} \\
Human & Umbilical cord blood mononuclear cells & Oct4, Sox2, KIf4, c-Myc & \\
\hline
\end{tabular}

iPSCs=Induced pluripotent stem cells

Veterinary World, EISSN: 2231-0916 
themselves to the host chromatin and replicates in synchrony with the host genome [36,37]. The episomal plasmids are naturally lost at up to $5 \%$ per cell division cycle. Thus, they can be utilized for a broader range of applications, including pre-clinical research, and human gene therapy [38].

\section{Transposons}

Two main transposable elements use in reprogramming are sleeping beauty and PiggyBac transposon [39]. Sleeping beauty originates from salmonides, where it remains as an inactive element and reawaken by an in vitro mutagenesis approach. Piggybac was identified as an active element in the moth Trichoplusia. Both elements show transposition activity in mammalian cells without cellular co-factors, but require DNA bending protein HMGB1 and cell cycle regulator Mizl for their functioning [40]. Both transposon systems have been shown to be suitable for the derivation of iPSCs in different cell lines.

\section{DNA-free delivery}

Reprogramming of cells can also achieved by employing recombinant protein rather than using genetic material directly to cells. These protein-based strategies have been successfully demonstrated but are much more complicated to perform as the generation and purification of protein in required quantity is a challenging task $[41,42]$. Reports on the generation of iPSCs through non-integrating methods are enlisted in Table-4 [32-46].

\section{Culture Conditions for iPSCs}

iPSCs have been established in ES cell media with LIF and bFGF as important factors for maintaining pluripotency [47]. $\mathrm{O}_{2}$ tension is also an influential aspect for stem cell maintenance and differentiation. Low $\mathrm{O}_{2}$ tension $\left(5 \% \mathrm{O}_{2}\right)$ condition, called hypoxia, promotes the reprogramming adequacy in both mouse and human fibroblasts [48]. Moreover, to boost the productivity of iPSCs and lessen the burden of exogenous factors, some natural and synthetic small molecules have been proved to be boon. These small molecules target signal transduction pathways that are involved in stem cell renewal and differentiation as Wnt pathway, tyrosine kinase receptor pathway affects epigenetic status of cells by modulating enzymes such as histone deacetylase, histone demethylase, histone methyltransferase, and DNA methyltransferase; DNA replication and other vital functions. Chemical compounds knock off some limitations of transcription factors based reprogramming approach and offer advantages as they are easily accessible to the cells, cost-effective and non-immunogenic $[36,49]$. A number of compounds have been determined that can take over the function of reprogramming transcription factors and thus, these chemicals have introduced a new window for generating clinical-grade iPSCs [50,51]. The different categories of compounds which are frequently employed in the fruitful generation of chemically iPSCs are mentioned in Table-5 [52-60].

\section{Application of iPSCs}

iPSCs possess the properties of differentiation and germline transmission, therefore have emerged as a substitute to stem cells in the field of biomedical sciences and research. Since iPSCs can bypass the ethical concerns pertained to ESC derivation and peril of allogeneic rejection; therefore, they serve as potential tools for clinical applications and medical research. Till date, iPSCs have accomplished practical applications in areas such as basic stem cell research, diseases modeling, regenerative medicine, drug discovery, and infertility treatment. iPSCs also have considerable applications in the field of animal research like the generation of transgenic animals, improving cloning efficiency, wildlife conservation, etc.

\section{Application in basic sciences}

The emergence of reprogramming techniques has resolved the relationship between transcription factors, signaling pathways, epigenetics, and

Table-4: Generation of iPSCs through non-integrating methods.

\begin{tabular}{|c|c|c|c|c|}
\hline Delivery vehicle & Species & Cell type & Genes involved & References \\
\hline Adenoviral vector & Mice & Tail tip fibroblasts & c-Myc, KIf4, Oct4, and Sox2 & {$[32]$} \\
\hline Adenoviral vector & Human & Fibroblasts & Ascl1, Brn3b and Ngn2 & [33] \\
\hline Sendai virus & Chimpanzee & Blood cells & Oct4, KIf4, Sox2, c-Myc & {$[34]$} \\
\hline Sendai virus & Human & Peripheral-T cells & Oct4, Sox2, KIf4, c-Myc & {$[35]$} \\
\hline Episomal plasmid & Human & Urine derived cells & Oct4, Sox2, KIf4, SV40LT, Lin28, c-Myc & {$[36]$} \\
\hline Episomal plasmid & Human & Blood & Oct4, Sox2, KIf4, c-Myc & {$[37]$} \\
\hline Episomal plasmid & Human & Leukocytes & Oct4, Sox2, KIf4 and SV40-T & {$[38]$} \\
\hline Piggybac transposon & Murine & Embryonic fibroblasts & Oct4, Sox2, KIf4, Lin28, c-Myc, Nanog & {$[39]$} \\
\hline Piggybac transposon & Bat & Embryonic fibroblasts & $\begin{array}{l}\text { Oct4, KIf4, Sox2, c-Myc, NR5A2, Nanog, } \\
\text { Lin28, and bat-specific miR302/367 }\end{array}$ & {$[40]$} \\
\hline Synthetic mRNA & Human and rat & Adult adipose-tissue & Oct4, Sox2, KIf4, and c-Myc & {$[41]$} \\
\hline Synthetic mRNA & Human & Fibroblasts & Oct4, Sox2, KIf4, and c-Myc & {$[42]$} \\
\hline Synthetic mRNA & Human & Fibroblasts & Oct4, Sox2, Klf4, and c-Myc and Glis1 & {$[43]$} \\
\hline Recombinant proteins & Mice & Embryonic fibroblasts & Oct4, Sox2, Klf4, and c-Myc & {$[44]$} \\
\hline Recombinant proteins & Human & Fibroblasts & Sox2, Nanog, KIf4 and NR5A2 & {$[45]$} \\
\hline Recombinant proteins & Human & Fibroblast & Oct4, Sox2, KIf4, and c-Myc & [46] \\
\hline
\end{tabular}

iPSCs=Induced pluripotent stem cells 
Table-5: Generation of iPSCs using chemical compounds.

\begin{tabular}{|c|c|c|c|}
\hline Modulating pathway & Chemical & Mechanism/target & References \\
\hline \multirow{2}{*}{ TGF- $\beta$} & RepSox (E-616452) & ALK5 inhibitor & {$[52]$} \\
\hline & SB431542 & ALK4, ALK5, ALK7 Inhibitor & [53] \\
\hline MAPK & PD0325901 & MEK1, MEK2 inhibitor & {$[54,55]$} \\
\hline PKA & Forskolin & PKA agonist & [50] \\
\hline Wnt & CHIR99021 & GSK3a, GSK3 ß inhibitor & {$[54,55]$} \\
\hline Nuclear receptor & TTNPB & Binds to retinoic acid receptor & {$[50]$} \\
\hline \multirow[t]{3}{*}{ Histone methylation } & BIX 01294 & Histone lysine methytransferase inhibitor & [56] \\
\hline & DZNep & Lysine methyltransferase EZH2 inhibitor & {$[50]$} \\
\hline & Tranylcypromine & Lysine specific demethylase 1 inhibitor & [54] \\
\hline \multirow[t]{4}{*}{ Histone deacetylation } & SAHA & Histone deacetylase inhibitor & [57] \\
\hline & Sodium butyrate & Histone deacetylase inhibitor & [58] \\
\hline & Trichostatin A & Histone deacetylase inhibitor & [58] \\
\hline & Valproic acid & Histone deacetylase inhibitor & [59] \\
\hline \multirow[t]{2}{*}{ Glycolysis } & 2,4-dinitrophenol & Oxidative phospholyration uncoupler & {$[60]$} \\
\hline & Fructose-2,6-bisphosphate & Phosphofructokinase 1 activator & [60] \\
\hline
\end{tabular}

iPSCs $=$ Induced pluripotent stem cells

transition states of the cell toward pluripotency. The MET and EMT transitions that a cell undergoes while reprogramming is a joint venture of action of core set of transcription factors which modulate the epigenetic state of cells and leads to an alteration in their gene expression. This study of developmental biology provides a roadmap for the process of embryogenesis, gastrulation and differentiation to other tissue types.

Also in the field of cancer research, reprogramming techniques are emerging as one of the most versatile tools to study the mechanistic modeling of human tumorigenesis. The process of reprogramming, pluripotency, lineage specification, and oncogenic transformations are fundamentally related to each other regarding the involvement of cancer-related genes $[61,62]$, pluripotency-associated genes and epigenetic related genes [63]. Many reports are available on iPSC lines derived from variety of human cancers, such as melanoma [64,65], prostate cancer [64], gastrointestinal cancers [66], chronic myeloid leukemia [67], lung cancer [68], breast cancer [69], glioblastoma [70], and sarcomas [71]. These patient-derived iPSCs can provide a better understanding of the niche for cancer progression and building a more relevant disease model. The iPSCs derived from banked cord blood from newborns have been employed to deduce the developmental and molecular mechanisms elementary for sequential progression of cancer from the precancerous cell [72]. Thus, iPSCs generated from cancerous cells can be used as model cell line to understand the elemental molecular mechanisms trailing for cancer initiation and progression and to overcome them.

\section{Cell transplantation/replacement therapy}

The applicability of iPSCs in regenerative medicine was demonstrated in 2007 by Hanna et al., where iPSCs were used to cure sickle cell anemia, a disease caused by single gene defect [73]. The disease-causing mutation was rectified by homologous recombination in iPSCs generated from mouse model. The repaired iPSCs then differentiated into blood-forming progenitor cells which were transplanted into anemic mice and disease was cured.

Since then many disease have been treated by iPSCs transplantation such as spinal cord injury [74], Parkinson's disease [75,76], hemophilia A [77], limb ischemia [78], acute myocardial infarction [79,80], peripheral vascular disease [81], diabetes [82], and regeneration [83]. In 2013, a group of scientists at the RIKEN Center for Developmental Biology launched the world's first clinical trial for the treatment of age-related macular degeneration which results in blindness due to the loss of retinal pigment epithelium. Scientists took skin cells from patients, converted them to iPSCs and then differentiated to retinal pigment epithelium cells. These cells were grown into thin sheets that can be transplanted to the damaged retina [84] (Figure-2).

\section{Disease modeling}

Patient-specific iPSCs serve as "a-patient-ina-dish" and can be differentiated to any type of body cell which is otherwise difficult to obtain such as brain cells and helps to understand how the disease works. Thus, they have resolved the problem regarding the availability of experimental material. Till date, various tissue specific iPSC derivatives have been generated such as hematopoietic $[85,86]$, hepatic $[87,88]$, endothelial [89], neurological [90-93], and cardiovascular cell lines $[71,94,95]$. Currently, iPSCs are used as disease models in research of a fatal neuromuscular disorder, spinal muscular atrophy (SMA). SMA patients have a defective SMN1 gene which results in loss of the motor neurons in the spinal cord, leading to muscle wasting, mobility impairment, and early death in children. Somatic cells from the patients suffering from SMA have been reprogrammed to generate SMA iPSCs which have the defective SMN1 gene and are being used as a model to study the onset of the disease in newly developing nerve cells. Furthermore, these SMA iPSCs are used to test a variety of new treatments instead of carrying out them directly on patients $[91,96]$. In addition, the lab-grown cells help in detecting the 


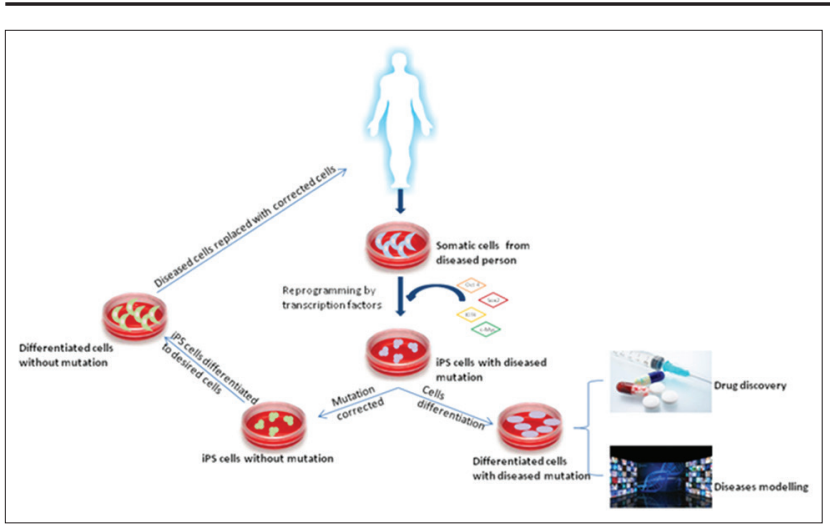

Figure-2: Application of induced pluripotent stem technology in medical science.

symptoms on the onset of diseases which are otherwise difficult to detect. Due to their practical application and successful results more and more diseases are modeled through iPSCs. Patients-specific iPS cell lines have been established for SMA [91], amyotrophic lateral sclerosis [90], familial hypertrophic cardiomyopathy (HCM) [97], $\beta$-thalassemia [98], Parkinson's disease $[99,100]$, Pompe disease [101], Rett syndrome [102], Lesch-Nyhan syndrome [103], LEOPARD syndrome [104], aldehyde dehydrogenase 2 genetic polymorphism $[105,106]$, arrhythmogenic right ventricular dysplasia [107,108], Timothy syndrome [95], long QT syndrome $[53,109,110]$, familial dilated cardiomyopathy [111], and viral cardiomyopathy [112].

\section{Drug screening and discovery}

A plausible assistance is provided by iPSC technology in the creation of a library of animal cell lines that comprises all the major genetic and epigenetic variants of a species. Cell lines derived from these iPSCs represents a realistic and more ideal drug model by creating a "disease-in-a-dish" model over hitherto employed patient's samples or immortalized tumor-derived cell lines. These well-defined, simulated models help in high-throughput screening of chemical compounds to identify relevant targets. The adoption of iPSCs dependent chemical screening has significantly reformed the success rate of drug development process [96]. After the primary screening, candidate targets are verified for secondary validation screening which holds their pharmacokinetic and safety properties [113]. Primary drug screening has been done for diseases, such as LEOPARD syndrome [104,114], SMA [91], familial dysautonomia [115], diabetic cardiomyopathy [116], neurological disease [117], amyotrophic lateral sclerosis [118], Familial transthyretin amyloidosis, NiemannPick disease type C, $\alpha 1$-antitrypsin deficiency, Wilson's disease [119], and umpteen diseases are under process.

\section{Treating infertility}

Pluripotent stem cells had opened a contemporary perspective in the treatment of patients with azoospermia. Using iPS technology, it is possible to get offspring with the same genetic material by derivation of functional male gametes from the infertile males themselves.
Recently, several studies have reported that both mouse iPSCs [120-122] and human iPSCs can differentiate into male germ cells $[123,124]$. It has been documented that mouse iPSCs can be differentiated to functional spermatozoa $[125,126]$. Experiments have been conducted to prove that spermatozoa derived from iPSCs are successful in fertilizing the oocytes after intracytoplasmic injection. Furthermore, there are reports available on the birth of fertile offspring following embryo transfer of such fertilized oocytes [125]. Thus, derivation of male germ cells from iPSCs epitomized mechanisms underlying the production of male gametes and their development, and also iPSCs have shown a ray of hope for confronting with infertility [127].

\section{iPSCs in veterinary science}

Among farm animals, pig is considered a valuable model for testing drugs and therapeutics before they are introduced to clinics [127]. Therefore, utilization of large animal models has a great potential in this field. Recently, mesenchymal stem cells derived from equine iPSCs were used as a model for pre-clinical validation of stem cell therapies for muscles, joints, tendons, ligaments, and bone injuries [128]. The iPS technology offers potential applications in veterinary sciences other than therapeutics and biomedical. This technique could be employed in assisted reproduction technology for increasing cloning efficiency using iPSCs as potent nucleus donors instead of somatic cells or ESCs $[23,129]$. These reprogrammed cells could boost up production of cloned animals and hence helps in conservation of endangered species. iPSCs also help in generation of chimeric and transgenic animals [130-133].

\section{Conclusion}

iPSCs have emerged as an alternative to stem cells in the field of biomedical sciences and research. Since iPSCs can omit the ethical concerns related to ESC derivation and potential issues of allogeneic rejection; therefore, the quintessential role of iPSCs leads to its use in therapy, drug development and clinical applications. The iPSCs hold great promise in the field of cell replacement therapy of diseases such as Alzheimer's disease, Parkinson's disease, cardiovascular disease, diabetes, and ALS. The iPS technology is a state-ofthe-art technique in the field of sciences which holds copious thought-provoking applications in biomedical research. For the maximal and pertinent application of this technique in clinical purposes, we require a more widespread knowledge about the pros and cons of the reprogramming process and hope for a better future.

\section{Authors' Contributions}

NR and MKS contributed the relevant literature in preparation of this review and approved the final manuscript.

\section{Acknowledgments}

This manuscript was prepared under the project "Generation of Induced Pluripotent Stem (iPS) like 
Cells from Buffalo Fibroblasts" supported by ICARNDRI, Karnal.

\section{Competing Interests} interests.

The authors declare that they have no competing

\section{References}

1. Martello, G. and Smith, A. (2014) Nature of embryonic stem cells annual review of cell and developmental biology. Cell. Dev. Biol., 30: 647-675.

2. Bernard, L. and Lindsay, P. (2009) Ethical issues in stem cell research. Endocr. Rev., 30(3): 204-213.

3. Wilmut, I., Schnieke, A.E., Mcwhir, J., Kind, A.J. and Campbell, K.H.S. (1997) Viable offspring derived from fetal and adult mammalian cells. Nature, 385: 810-813.

4. Silva, J., Chambers, I., Pollard, S. and Smith, A. (2006) Nanog promotes transfer of pluripotency after cell fusion. Nature, 441: 997-1001.

5. Pralong, D., Trounson, A.O. and Verma, P.J. (2006) Cell fusion for reprogramming pluripotency: Toward elimination of the pluripotent genome. Stem Cell Rev., 2(4): 331-340.

6. Yamanaka, S. and Blau, H.M. (2010) Nuclear reprogramming to a pluripotent state by three approaches. Nature, 465(7299): 704-712.

7. Bilic, J., Carlos, J. and Belmonte, I. (2011) Concise review: Induced pluripotent stem cells versus embryonic stem cells: Close enough or yet too far apart? Stem Cells, 30(1): 33-41.

8. Joo, J.Y., Choi, H.W., Kim, M.J., Zaehres, H., Tapia, N., Stehling, M., Jung, K.S., Do, J.T. and Scholer, H.R. (2014) Establishment of a primed pluripotent epiblast stem cell in FGF4-based conditions. Sci. Rep., 4: 7477.

9. Weinberger, L., Ayyash, M., Novershtern, N. and Hanna, J.H. (2016) Dynamic stem cell states: Naive to primed pluripotency in rodents and humans. Nat. Rev. Mol. Cell. Biol., 17: 155-169.

10. Li, X., Pei, D. and Zheng, H. (2014) Transitions between epithelial and mesenchymal states during cell fate conversions. Prote. Cell, 5(8): 580-591.

11. Hawkins, K., Joy, S. and McKay, T. (2014) Cell signalling pathways underlying induced pluripotent stem cell reprogramming. World J. Stem Cells., 6(5): 620-628.

12. Maherali, N. and Hochedlinger, K. (2009) TGF beta signal inhibition cooperates in the induction of iPSCs and replaces Sox2 and cMyc. Curr Biol., 19: 1718-1723.

13. Jiao, J., Dang, Y., Yang, Y., Gao, R., Zhang, Y., Kou, Z., Sun, X.F. and Gao, S. (2013) Promoting reprogramming by FGF2 reveals that the extracellular matrix is a barrier for reprogramming fibroblasts to pluripotency. Stem Cells, 31: 729-740.

14. Chambers, I. and Tomlinson, S.R. (2009) The transcriptional foundation of pluripotency. Development, 136: 2311-2322.

15. Niwa, H., Miyazaki, J. and Smith, A.G. (2000) Quantitative expression of Oct-3/4 defines differentiation, dedifferentiation or self-renewal of ES cells. Nat. Genet., 24: 372-376.

16. Takahashi, K. and Yamanaka, S. (2006) Induction of pluripotent stem cells from mouse embryonic and adult fibroblast cultures by defined factors. Cell, 126: 663-676.

17. Okita, K. Ichisaka, T. and Yamanaka, S. (2007) Generation of germline-competent induced pluripotent stem cells. Nature, 448: 313-317.

18. Wernig, M. (2007) In vitro reprogrammed fibroblasts have a similar developmental potential as ES cells and an ES celllike epigenetic state. Nature, 448: 313-317.

19. Du, D. and Lou, X. (2014) Generation of induced pluripotent stem cells from neonatal mouse cochlear cells. Differentiation, 87: 127-133.

20. Koh, S. and Piedrahita, J.A. (2015) Generation of induced pluripotent stem cells (iPSCs) from adult canine fibroblasts methods. Mol. Biol., 1330: 69-78.
21. Esteban, M.A., Xu, J., Yang, J., Peng, M., Qin, D., Li, W., Jiang, Z., Chen, J., Deng, K., Zhong, M., Cai, J., Lai, L. and Pei, D. (2009) Generation of induced pluripotent stem cell lines from Tibetan miniature pig. J. Biol. Chem., 284(26): 17634-17640.

22. Fujishiro, S.H., Nakano, K., Mizukami, Y., Azami, T., Arai, Y., Matsunari, H., Ishino, R., Nishimura, T., Watanabe, M., Abe, T., Furukawa, Y., Umeyama, K., Yamanaka, S., Ema, M., Nagashima, H. and Hanazono, Y. (2013) Generation of naive-like porcine-induced pluripotent stem cells capable of contributing to embryonic and fetal development. Stem Cells Dev., 22(3): 473-482.

23. Han, X., Han, J., Ding, F., Cao, S., Lim, S.S., Dai, Y., Zhang, R., Zhang, Y., Lim, B. and Li, N. (2011) Generation of induced pluripotent stem cells from bovine embryonic fibroblast cells. Cell Res., 21: 1509-1512.

24. Deng, Y., Liu, Q., Luo, C., Chen, S., Li, X., Wang, C., Liu, Z., Lei, X., Zhang, H., Sun, H., Lu, F., Jiang, J. and Shi, D. (2012) Generation of induced pluripotent stem cells from buffalo (Bubalus bubalis) fetal fibroblasts with buffalo defined factors. Stem Cells Dev., 21(13): 2485-2494.

25. Imamura, M., Okuno, H., Tomioka, I., Kawamura, Y., Lin, Z.Y., Nakajima, R., Akamatsu, W., Okano, J., Matsuzaki, Y., Sasaki, E. and Okano, H. (2012) Derivation of induced pluripotent stem cells by retroviral gene transduction in mammalian species. Methods Mol. Biol., 925: $21-48$

26. Takahashi, K., Tanabe, K., Ohnuki, M., Narita, M., Ichisaka, T., Tomoda, K. and Yamanaka, S. (2007) Induction of pluripotent stem cells from adult human fibroblasts by defined factors. Cell, 131(5): 861-872.

27. Ninagawa, N.T., Kawabata, Y., Watanabe, S., Nagata, K. and Torihashi, S. (2014) Generation of rat-induced pluripotent stem cells from a new model of metabolic syndrome. Plos One, 9(8): e104462.

28. Honda, A., Hatori, M., Hirose, M., Honda, C., Izu, H., Inoue, K., Hirasawa, R., Matoba, S., Togayachi, S., Hiroyuki, M. and Atsuo, O. (2013) Naïve-like conversion overcomes the limited differentiation capacity of induced pluripotent stem cells. J. Biol. Chem., 288(36): 26157-26166.

29. Sandmaier, S.E., Nandal, A., Powell, A., Garrett, W., Blomberg, L., Donovan, D.M., Talbot, N. and Telugu, B.P. (2015) Generation of induced pluripotent stem cells from domestic goats. Mol. Reprod. Dev., 82(9): 709-721.

30. Cao, H., Yang, P., Pu, Y., Sun, X., Yin, H., Zhang, Y., Zhang, Y., Li, Y., Liu, Y., Fang, F., Zhang, Z., Tao, Y. and Zhang, X. (2012) Characterization of bovine induced pluripotent stem cells by lentiviral transduction of reprogramming factor fusion proteins. Int. J. Biol. Sci., 8(4): 498-511.

31. Wang, J., Gu, Q., Hao, J., Bai, D., Liu, L., Zhao, X., Liu, Z., Wang, L. and Zhou, Q. (2013) Generation of induced pluripotent stem cells with high efficiency from human umbilical cord blood mononuclear cells. Dev. Reprod. Biol., 11(5): 304-311.

32. Sommer, C.A., Sommer, A.G., Longmire, T.A., Christodoulou, C., Thomas, D.D., Gostissa, M., Alt, F.W., Murphy, G.J., Kotton, D.N. and Mostoslavsky, G. (2.010) Excision of reprogramming transgenes improves the differentiation potential of iPS cells generated with a single excisable vector. Stem Cells, 28(1): 64-74.

33. Meng, F., Wang, X., Gu, P., Wang, Z. and Guo, W. (2013) Induction of retinal ganglion-like cells from fibroblasts by adenoviral gene delivery. Neuroscience, 250: 381-393.

34. Fujie, Y., Fusaki, N., Katayama, T., Hamasaki, M., Soejima, Y., Soga, M., Ban, H., Hasegawa, M., Yamashita, S., Kimura, S., Suzuki, S., Matsuzawa, T., Akari, H. and Takumi, E. (2014) New type of Sendai virus vector provides transgene-free iPS cells derived from chimpanzee blood. PLoS One, 9(12): e113052.

35. Kishino, Y., Seki, T., Yuasa, S., Fujita, J. and Fukuda, K. (2015) Generation of induced pluripotent stem cells from human peripheral T cells using Sendai virus in feeder-free conditions. J. Vis. Exp., 11(105): e53225. 
36. Xue, Y., Cai, X., Wang, L., Liao, B., Zhang, H., Shan, Y., Chen, Q., Zhou, T., Li, X., Hou, J., Chen, S., Luo, R., Qin, D., Pei, D. and Pan, G. (2013) Generating a non-integrating human induced pluripotent stem cell bank from urine-derived cells. PLoS One, 8(8): e70573.

37. Wen, W., Zhang, J., Xu, J., Su, R.J., Neises, A., Ji, G.Z., Yuan, W., Cheng, T. and Zhang, X.B. (2016) Enhanced generation of integration-free iPSCs from human adult peripheral blood mononuclear cells with an optimal combination of episomal vectors. Stem Cell Rep., 6(6): 873-884.

38. Meraviglia, V., Zanon, A., Lavdas, A.A., Schwienbacher, C., Silipigni, R., Segni, M., Chen, H.S., Pramstaller, P.P., Hicks, A.A. and Rossini, A. (2015) Generation of induced pluripotent stem cells from frozen buffy coats using non-integrating episomal plasmids. J. Vis. Exp., 5(100): e52885.

39. Talluri, T.R., Kumar, D., Glage, S., Garrels, W., Ivics, Z., Debowski, K., Behr, R., Niemann, H. and Kues, W.A. (2015) Derivation and characterization of bovine induced pluripotent stem cells by transposon-mediated reprogramming. Cell Reprogram., 17(2): 131-140.

40. Mo, X., Li, N. and Wu, S. (2014) Generation and characterization of bat-induced pluripotent stem cells. Theriogenology, 82(2): 283-293.

41. Choi, H.Y., Lee, T.J., Yang, G.M., Oh, J., Won, J., Han, J., Jeong, G.J., Kim, J., Kim, J.H., Kim, B.S. and Cho, S.G. (2016) Efficient mRNA delivery with graphene oxide-polyethylenimine for generation of footprint-free human induced pluripotent stem cells. J. Controll Release, 235: 222-235.

42. Preskey, D., Allison, T.F., Jones, M., Mamchaoui, K. and Unger, C. (2016) Synthetically modified mRNA for efficient and fast human iPS cell generation and direct trans differentiation to myoblasts. Biochem. Biophys. Res. Commun., 473(3): 743-751.

43. Yoshioka, N., Gros, E., Li, R., Kumar, S., Deacon, D.C., Maron, C., Muotri, A.R., Chi, N.C., Fu, X.D., Yu, B.D. and Dowdy, S.F. (2013) Efficient generation of human iPS cells by a synthetic self replicative RNA. Cell Stem Cell, 13(2): 246-254.

44. Nemes, C., Varga, E., Polgar, Z., Klincumhom, N., Pirity, M.K. and Dinnyes, A. (2014) Generation of mouse induced pluripotent stem cells by protein transduction. Tissue Eng. Methods, 20(5): 383-392.

45. Khan, M., Narayana, K., Lu, H., Choo, Y., Du, C., Wiradharma, N., Yang, Y.Y. and Wan, A.C. (2013) Delivery of reprogramming factors into fibroblasts for generation of non-genetic induced pluripotent stem cells using a cationic bolaamphiphile as a non-viral vector. Biomaterials, 34: 5336-5343.

46. Cho, S.J., Choi, H.W., Cho, J., Jung, S., Seo, H.G. and Do, J.T. (2013) Activation of pluripotency genes by a nanotube-mediated protein delivery system. Mol. Reprod., 80(12): 1000-1008.

47. Hirai, H., Firpo, M. and Kikyo, N. (2012) Establishment of LIF-dependent human iPS cells closely related to basic FGF-dependent authentic iPS cells. PLoS One, 7(6): e39022.

48. Mohyeldin, A., Garzon, M.T. and Quinones, H.A. (2010) Oxygen in stem cell biology: A critical component of the stem cell niche. Cell Stem Cell, 7(2): 150-161.

49. Zhang, Z. and Wu, W.S. (2013) Sodium butyrate promotes generation of human induced pluripotent stem cells through induction of the miR302/367 cluster. Stem Cells Dev., 22: 2268-2277.

50. Hou, P., Li, Y., Zhang, X., Liu, C., Guan, J., Li, H., Zhao, T., Ye, J., Yang, W. and Liu, K. (2013) Pluripotent stem cells induced from mouse somatic cells by small-molecule compounds. Science, 341: 651-654.

51. Wu, Y.L., Pandian, G.N., Ding, Y.P., Zhang, W., Tanaka, Y. and Sugiyama, H. (2013) Clinical grade iPS cells: Need for versatile small molecules and optimal cell sources. Chem. Biol., 20: 1311-1322.

52. Ichida, J.K., Blanchard, J., Lam, K., Son, E.Y., Chung, J.E.,
Egli, D., Loh, K.M., Carter, A.C., Giorgio, K.K., Huangfu, D., Akutsu, H., Liu, D.R., Rubin, L.L. and Eggan, K. (2009) A small molecule inhibitor of TGF- $\beta$ signaling replaces Sox 2 in reprogramming by inducing nanog. Cell Stem Cell, 5(5): 491-503.

53. Wang, Y., Liang, P., Lan, F., Wu, H., Lisowski, L., Gu, M., Hu, S., Kay, M.A., Urnov, F.D. and Shinnawi, R. (2014) Genome editing of isogenic human induced pluripotent stem cells recapitulates long QT phenotype for drug testing. J. Am. Coll. Cardiol., 64: 451-459.

54. Li, D., Wang, L., Hou, J., Shen, Q., Chen, Q., Wang, X., Du, J., Cai, X., Shan, Y., Zhang, T., Zhou, T., Shi, X., Li, Y., Zhang, H. and Guangjin, P. (2016) Optimized approaches for generation of integration-free iPSCs from human urine-derived cells with small molecules and autologous feeder. Stem Cell Rep., 6: 717-728.

55. Lin, T., Ambasudhan, R., Yuan, X., Li, W., Hilcove, S., Abujarour, R., Lin, X., Hahm, H.S., Hao, E. and Hayek, A. (2009) A chemical platform for improved induction of human iPSCs. Nat. Methods, 6: 805-808

56. Shi, Y., Desponts, C., Do, J.T., Hahm, H.S., Scholer, H.R. and Ding, S. (2008) Induction of pluripotent stem cells from mouse embryonic fibroblasts by October 4 and Klf4 with small-molecule compounds. Cell Stem Cell, 3(5): 568-574.

57. Pandian, G.N., Sato, S., Anandha, K., Taniguchi, J., Takashima, K., Syed, J., Han, L., Saha, A., Bando, T. and Nagase, H. (2014) Identification of a small molecule that turns on the pluripotency gene circuitry in human fibroblasts. ACS Chem. Biol., 9: 2729-2736.

58. Debeb, B.G., Lacerda, L., Xu, W., Larson, R., Solley, T., Atkinson, R., Sulman, E.P., Ueno, N.T., Krishnamurthy, S., Reuben, J.M., Buchholz, T.A. and Woodward, W.A. (2012) Histone deacetylase inhibitors stimulate dedifferentiation of human breast cancer cells through WNT/ $\beta$-catenin signalling. Stem Cells, 30(11): 2366-2377.

59. Zhai, Y., Chen, X., Yu, D., Li, T., Cui, J., Wang, G., Hu, J.F. and $\mathrm{Li}, \mathrm{W}$. (2015) Histone deacetylase inhibitor valproic acid promotes the induction of pluripotency in mouse fibroblasts by suppressing reprogramming-induced senescence stress. Exp. Cell Res., 337: 61-67.

60. Vazquez, M.A., Corominas, F.B., Cufi, S., Vellon, L., Oliveras, F.C., Menendez, O.J., Joven, J., Lupu, R. and Menendez, J.A. (2013) The mitochondrial H(+)-ATP synthase and the lipogenic switch: New core components of metabolic reprogramming in induced pluripotent stem (iPS) cells. Cell Cycle, 12(2): 207-18.

61. Bernhardt, M., Galach, M., Novak, D. and Utikal, J. (2012) Mediators of induced pluripotency and their role in cancer cells-current scientific knowledge and future perspectives. Biotechnol. J., 7: 810-821.

62. Lee, D.F., Su, J., Kim, H.S., Chang, B., Papatsenko, D., Zhao, R., Yuan, Y., Gingold, J., Xia, W., Darr, H., Mirzayans, R., Hung, M.C., Schanie, C., Ihor, R. and Lemischka, I.R. (2015) Modeling familial cancer with induced pluripotent stem cells. Cell, 161(2): 240-254

63. Berdasco, M. and Esteller, M. (2010) Aberrant epigenetic landscape in cancer: How cellular identity goes awry. Dev. Cell., 19: 698-711.

64. Lin, S.L., Chang, D.C. and Chang, L.S. (2008) Mir-302 reprograms human skin cancer cells into a pluripotent ES-cell-like state. $R N A, 14: 2115-2124$.

65. Utikal, J., Maherali, N., Kulalert, W. and Hochedlinger, K. (2009) Sox 2 is dispensable for the reprogramming of melanocytes and melanoma cells into induced pluripotent stem cells. J. Cell Sci., 122: 3502-3510.

66. Miyoshi, N., Ishii, H. and Nagai, K. (2010) Defined factors induce reprogramming of gastrointestinal cancer cells. Proc. Natl. Acad. Sci., 107: 40-45.

67. Carette, J.E., Pruszak, J., Varadarajan, M. (2010) Generation of iPSCs from cultured human malignant cells. Blood, 115: 4039-4042.

68. Mathieu, J., Zhang, Z. and Zhou, W. (2011) HIF induces 
human embryonic stem cell markers in cancer cells. Cancer Res., 71: 4640-4652.

69. Corominas, F.B., Cufi, S. and Oliveras, F.C. (2013) Nuclear reprogramming of luminal-like breast cancer cells generates Sox2-overexpressing cancer stem-like cellular states harboring transcriptional activation of the mTOR pathway. Cell Cycle, 12: 3109-3124.

70. Stricker, S.H., Feber, A. and Engstrom, P.G. (2013) Widespread resetting of DNA methylation in glioblastoma-initiating cells suppresses malignant cellular behaviour in a lineage-dependent manner. Genes Dev., 27: 654-669.

71. Zhang, J. (2011) A human iPSC model of hutchinson gilford progeria reveals vascular smooth muscle and mesenchymal stem cell defects. Cell Stem Cell, 8(1): 31-45.

72. Broxmeyer, H.E. (2010) Will iPS cells enhance therapeutic applicability of cord blood cells and banking? Cell Stem Cell, 6: 21-24.

73. Hanna, J., Wernig, M., Markoulaki, S., Sun, C.W., Meissner, A., Cassady, J.P., Beard, C., Brambrink, T., Wu, L.C., Townes, T.M. and Jaenisch, R. (2007) Treatment of sickle cell anemia mouse model with iPS cells generated from autologous skin. Science, 318(5858): 1920-1923.

74. Tsuji, O., Miura, K., Okada, Y., Fujiyoshi, K., Mukaino, M., Nagoshi, N., Kitamura, K., Kumagai, G., Nishino, M. and Tomisato, S. (2010) Therapeutic potential of appropriately evaluated safe induced pluripotent stem cells for spinal cord injury. Proc. Natl. Acad. Sci., 107: 12704-12709.

75. Wernig, M., Zhao, J.P., Pruszak, J., Hedlund, E., Fu, D., Soldner, F., Broccoli, V., Paton, M., Isacson, O. and Jaenisch, R. (2008) Neurons derived from reprogrammed fibroblasts functionally integrate into the fetal brain and improve symptoms of rats with Parkinson's disease. Proc. Natl. Acad. Sci., 105: 5856-5861.

76. Swistowski, A., Peng, J., Liu, Q., Mali, P., Rao, M.S., Cheng, L. and Zeng, X. (2010) Efficient generation of functional dopaminergic neurons from human induced pluripotent stem cells under defined conditions. Stem Cells, 28: 1893-1904.

77. Xu, D., Alipio, Z., Fink, L.M., Adcock, D.M., Yang, J., Ward, D.C. and Ma, Y. (2009) Phenotypic correction of murine hemophilia A using an iPS cell-based therapy. Proc. Natl. Acad. Sci., 106: 808-813.

78. Kang, S., Xia, J.C. and Lai, W. (2010) Functional mesenchymal stem cells derived from human induced pluripotent stem cells attenuate limb ischemia in mice. Circulation, 121: $1113-1123$

79. Nelson, T.J., Martinez, F.A., Yamada, S., Perez, T.C., Ikeda, Y. and Terzic, A. (2009) Repair of acute myocardial infarction by human stemness factors induced pluripotent stem cells. Circulation, 120: 408-416.

80. Funakoshi, S., Miki, K., Takaki, T., Okubo, C., Hatani, T., Chonabayashi, K., Nishikawa, M., Takei, I., Oishi, A., Narita, M., Hoshijima, M., Kimura, T., Yamanaka, S. and Yoshida, Y. (2016) Enhanced engraftment, proliferation, and therapeutic potential in heart using optimized human iPSC-derived cardiomyocytes. Sci. Rep., 6: 19111.

81. Rufaihah, A.J., Huang, N.F., Jame, S., Lee, J.C., Nguyen, H.N., Byers, B., De, A., Okogbaa, J., Rollins, M. and Reijo, R. (2011) Endothelial cells derived from human iPSCS increase capillary density and improve perfusion in a mouse model of peripheral arterial disease. Arterioscler Thromb. Vasc. Biol., 31: 72-79.

82. Alipio, Z., Liao, W., Roemer, E.J., Waner, M., Fink, L.M., Ward, D.C. and Ma, Y. (2010) Reversal of hyperglycemia in diabetic mouse models using induced-pluripotent stem (iPS)-derived pancreatic $\beta$-like cells. Proc. Natl. Acad. Sci., 107(30): 13426-13431.

83. Liu, H., Kim, Y., Sharkis, S., Marchionni, L. and Jang, Y.Y. (2011) In vivo liver regeneration potential of human induced pluripotent stem cells from diverse origins. Sci. Transl. Med., 3(82): 82-39.

84. Garber, K. (2015) RIKEN suspends first clinical trial involving induced pluripotent stem cells. Nat. Biotechnol., 33: $890-891$

85. Urbach, A. (2010) Differential modeling of fragile X syndrome by human embryonic stem cells and induced pluripotent stem cells. Cell Stem Cell, 6(5): 407-411.

86. Tolar, J., Park, I.H., Xia, L., Lees, C.J., Peacock, B., Webber, B., McElmurry, R.T., Eide, C.R., Orchard, P.J., Kyba, M., Osborn, M.J., Lund, T.C., Wagner, J.E., Daley, G.Q. and Blazar, B.R. (2011) Hematopoietic differentiation of induced pluripotent stem cells from patients with mucopolysaccharidosis type I (Hurler syndrome). Blood, 117(3): 839-847.

87. Liu, H. (2010) Generation of endoderm derived human induced pluripotent stem cells from primary hepatocytes. Hepatology, 51(5): 1810-1819.

88. Sullivan, G.J. (2010) Generation of functional human hepatic endoderm from human induced pluripotent stem cells. Hepatology, 51(1): 329-335.

89. Li, Z., Hu, S., Ghosh, Z., Han, Z. and Wu, J.C. (2011) Functional characterization and expression profiling of human induced pluripotent stem cell and embryonic stem cell derived endothelial cells. Stem Cells Dev., 20(10): 1701-1710.

90. Dimos, J.T. (2008) Induced pluripotent stem cells generated from patients with ALS can be differentiated into motor neurons. Science, 321(5893): 1218-1221.

91. Ebert, A.D., Yu, J., Rose, F.F., Mattis, V.B., Lorson, C.L., Thomson, J.A. and Svendsen, C.N. (2009) Induced pluripotent stem cells from a spinal muscular atrophy patient. Nature, 457: 277-280.

92. Marchetto, M.C. (2010) A model for neural development and treatment of Rett syndrome using human induced pluripotent stem cells. Cell, 143(4): 527-539.

93. Chamberlain, S.J. (2010) Induced pluripotent stem cell models of the genomic imprinting disorders Angelman and Prader Willi syndromes. Proc. Natl. Acad. Sci., 107(41): 17668-17673.

94. Narsinh, K., Narsinh, K.H. and Wu, J.C. (2011) Derivation of human induced pluripotent stem cells for cardiovascular disease modelling. Circ. Res., 108(9): 1146-1156.

95. Yazawa, M., Hsueh, B., Jia, X., Pasca, A.M., Bernstein, J.A., Hallmayer, J. and Dolmetsch, R.E. (2011) Using induced pluripotent stem cells to investigate cardiac phenotypes in Timothy syndrome. Nature, 471: 230-234.

96. Ebert, A.D., Liang, P. and Wu, J.C. (2012) Induced pluripotent stem cells as a disease modelling and drug screening platform. J Cardiovasc. Pharmacol., 60: 408-416.

97. Lan, F., Lee, A.S., Liang, P., Sanchez, V., Nguyen, P.K., Wang, L., Han, L., Yen, M., Wang, Y. and Sun, N. (2013) Abnormal calcium handling properties underlie familial hypertrophic cardiomyopathy pathology in patient-specific induced pluripotent stem cells. Cell Stem Cell, 12: 101-113.

98. Ye, L., Chang, J.C., Lin, C., Sun, X., Yu, J. and Kan, Y.W. (2009) Induced pluripotent stem cells offer new approach to therapy in thalassemia and sickle cell anemia and option in prenatal diagnosis in genetic diseases. Proc. Natl. Acad. Sci., 106(24): 9826-9830.

99. Soldner, F., Hockemeyer, D., Beard, C., Gao, Q., Bell, G.W., Cook, E.G., Hargus, G., Blak, A., Cooper, O. and Mitalipova, M. (2009) Parkinson's disease patient-derived induced pluripotent stem cells free of viral reprogramming factors. Cell, 136(5): 964-977.

100. Kang, J., Tang, B. and Guo, J. (2016) The progress of induced pluripotent stem cells as models of Parkinson's disease. Stem Cells Int., 2016: Article ID: 4126214, 1-6.

101. Sato, Y., Kobayashi, H., Higuchi, T., Shimada, Y., Era, T., Kimura, S., Eto, Y., Ida, H. and Ohashi, T. (2015) Disease modelling and lentiviral gene transfer in patient specific induced pluripotent stem cells from late onset Pompe disease patient. Mol. Ther. Methods Clin. Dev., 2: 15023.

102. Hotta, A., Cheung, A.Y., Farra, N., Vijayaragavan, K., Séguin, C.A., Draper, J.S., Pasceri, P., Maksakova, I.A., 
Mager, D.L., Rossant, J., Bhatia, M. and Ellis, J. (2009) Isolation of human iPS cells using EOS lentiviral vectors to select for pluripotency. Nat. Methods, 6(5): 370-376.

103. Park, I.H., Arora, N., Huo, H., Maherali, N., Ahfeldt, T., Shimamura, A., Lensch, M.W., Cowan, C., Hochedlinger, K. and Daley, G.Q. (2008) Disease-specific induced pluripotent stem (iPS) cells. Cell, 134(5): 877-886.

104. Carvajal, V.X., Sevilla, A., D’Souza, S.L., Ang, Y.S., Schaniel, C., Lee, D.F., Yang, L., Kaplan, A.D., Adler, E.D. and Rozov, R. (2010) Patient-specific induced pluripotent stem-cell-derived models of LEOPARD syndrome. Nature, 465: 808-812.

105. Ebert, A.D., Kodo, K., Liang, P., Wu, H., Huber, B.C., Riegler, J., Churko, J., Lee, J., Almeida, P. and Lan, F. (2014) Characterization of the molecular mechanisms underlying increased ischemic damage in the aldehyde dehydrogenase 2 genetic polymorphism using a human induced pluripotent stem cell model system. Sci. Transl. Med., 6: 255.

106. Ebert, A.D., Diecke, S., Chen, I.Y. and Wu, J.C. (2015) Reprogramming and transdifferentiation for cardiovascular development and regenerative medicine: Where do we stand? EMBO Mol. Med., 7(9): 1090-1103.

107. Kim, C., Wong, J., Wen, J., Wang, S., Wang, C., Spiering, S., Kan, N.G., Forcales, S., Puri, P.L. and Leone, T.C. (2013) Studying arrhythmogenic right ventricular dysplasia with patient-specific iPSCs. Nature, 494: 105-110.

108. Asimaki, A., Kapoor, S., Plovie, E., Karin, A.A., Adams, E., Liu, Z., James, C.A., Judge, D.P., Calkins, H. and Churko, J. (2014) Identification of a new modulator of the intercalated disc in a zebrafish model of arrhythmogenic cardiomyopathy. Sci. Transl. Med., 6(240): 261-266.

109. Moretti, A., Bellin, M., Welling, A., Jung, C.B., Lam, J.T., Bott, F.L., Dorn, T., Goedel, A., Hohnke, C. and Hofmann, F. (2010) Patient-specific induced pluripotent stem-cell models for long-QT syndrome. N. Engl. J. Med., 363: 1397-1409.

110. Itzhaki, I., Maizels, L., Huber, I., Dantsis, L., Caspi, O., Winterstern, A., Feldman, O., Gepstein, A., Arbel, G. and Hammerman, H. (2011) Modelling the long QT syndrome with induced pluripotent stem cells. Nature, 471: 225-229.

111. Sun, N., Yazawa, M., Liu, J., Han, L., Sanchez, F.V., Abilez, O.J., Navarrete, E.G., Hu, S., Wang, L. and Lee, A. (2012) Patient-specific induced pluripotent stem cells as a model for familial dilated cardiomyopathy. Sci. Transl. Med., 4(130): 130-147.

112. Sharma, A., Marceau, C., Hamaguchi, R., Burridge, P.W., Rajarajan, K., Churko, J.M., Wu, H., Sallam, K.I., Matsa, E. and Sturzu, A.C. (2014) Human induced pluripotent stem cell-derived cardiomyocytes as an in vitro model for coxsackievirus B3-induced myocarditis and antiviral drug screening platform. Circ. Res., 115: 556-566.

113. Dick, E. (2010) Evaluating the utility of cardiomyocytes from human pluripotent stem cells for drug screening. Biochem. Soc. Trans., 38(4): 1037-1045.

114. Zhao, J., Jiang, W.J., Chen, S., Hou, C.Z., Yang, X.M. and Gao, J.G. (2013) Induced pluripotent stem cells: Origins, applications, and future perspectives. Biomed. Biotechnol., 14(12): 1059-1069.

115. Lee, G., Papapetrou, E.P., Kim, H., Chambers, S.M., Tomishima, M.J., Fasano, C.A., Ganat, Y.M., Menon, J., Shimizu, F. and Viale, A. (2009) Modelling pathogenesis and treatment of familial dysautonomia using patient specific iPS cells. Nature, 461(7262): 402-406.

116. Drawnel, F.M., Boccardo, S., Prummer, M., Delobel, F., Graff, A., Weber, M., Gérard, R., Thong, L.B., Bu, L., Jiang, X., Hoflack, J.C., Kiialainen, A., Jeworutzki, E., Aoyama, N., Carlson, C., Burcin, M., Gromo, G., Boehringer, M., Stahlberg, H., Hall, B.J., Magnone, M.C., Kolaja, K., Chien, K.R., Bailly, J. and Iacone, R. (2014)
Disease modelling and phenotypic drug screening for diabetic cardiomyopathy using human induced pluripotent. Stem Cell Rep., 9: 810-820.

117. Xu, X.H. and Zhong, Z. (2013) Disease modelling and drug screening for neurological diseases using human induced pluripotent stem cells. Acta Pharmacol. Sin., 34: 755-764.

118. Egawa, N., Kitaoka, S., Tsukita, K., Naitoh, M., Takahashi, K., Yamamoto, T., Adachi, F., Kondo, T., Okita, K., Asaka, I., Aoi, T., Watanabe, A., Yamada. Y., Morizane, A., Takahashi, J., Ayaki, T., Ito, H., Yoshikawa, K., Yamawaki, S., Suzuki, S., Watanabe, D., Hioki, D., Kaneko, T., Makioka, K., Okamoto, K., Takuma, H., Tamaoka, A., Hasegawa, K., Nonaka, T., Hasegawa, M., Kawata, A., Yoshida, M., Nakahata, T., Takahashi, R., Marchetto, M.C., Gage, F.H., Yamanaka, S. and Inoue, H. (2012) Drug screening for ALS using patient-specific induced pluripotent stem cells. Sci. Transl. Med., 4(145): 145.

119. Davidson, M.D., Ware, B.R. and Khetani, S.R. (2015) Stem cell-derived liver cells for drug testing and disease modelling. Discov. Med., 19(106): 349-358.

120. Zhu, Y., Hu, L. and Li, P. (2012) Generation of male germ cells from induced pluripotent stem cells (iPS cells): An in vitro and in vivo study. Asian J. Androl., 14(4): 574-579.

121. Yang, S., Bo, J. and Hu, H. (2012) Derivation of male germ cells from induced pluripotent stem cells in vitro and in reconstituted seminiferous tubules. Cell Prolif., 45(2): 91-100.

122. Li, P., Hu, H. and Yang, S. (2013) Differentiation of induced pluripotent stem cells into male germ cells in vitro through embryoid body formation and retinoic acid or testosterone induction. Bio Med. Res. Int. 2013: 608728.

123. Malik, N. and Rao, M.S. (2013) A review of the methods for human iPSC derivation. Methods Mol. Biol., 997: 23-33.

124. Xu, X., Yi, F.Z. and Pan, H. (2013) Progress and prospects in stem cell therapy. Acta Pharmacol. Sin., 34(6): 741-746.

125. Hayashi, K., Ohta, H., Kurimoto, K., Aramaki, S. and Saitou, M. (2011) Reconstitution of the mouse germ cell specification pathway in culture by pluripotent stem cells. Cell, 146(4): 519-532.

126. Ohinata, Y., Ohta, H., Shigeta, M., Yamanaka, K., Wakayama, T. and Saitou, M. (2009) A signaling principle for the specification of the germ cell lineage in mice. Cell, 137(3): 571-584.

127. Volarevic, V., Bojic, S., Nurkovic, J., Volarevic, A., Ljujic, B., Arsenijevic, N., Lako, M. and Stojkovic, M. (2014) Stem cells as new agents for the treatment of infertility: Current and future perspectives and challenges. Bio Med. Res. Int., 2014: 507234-507238.

128. Brevini, T.A., Antonini, S., Cillo, F., Crestan, M. and Gandolfi, F. (2007) Porcine embryonic stem cells: Facts, challenges and hopes. Theriogenology, 68: 206-213.

129. Nagy, K., Sung, H.K., Zhang, P., Laflamme, S., Vincent, P. and Mohammadi, S. (2011) Induced pluripotent stem cell lines derived from equine fibroblasts. Stem Cell Rev., 7: 693-702.

130. Fan, N., Chen, J., Shang, Z., Dou, H., Ji, G. and Zou, Q. (2013) Piglets cloned from induced pluripotent stem cells. Cell Res., 23: 162-166.

131. West, F.D., Terlouw, S.L., Kwon, D.J., Mumaw, J.L., Dhara, S.K., Hasneen, K., Dobrinsky, J.R. and Stice, S.L. (2010) Porcine induced pluripotent stem cells produce chimeric off springs. Stem Cells Dev., 19(8): 1211-1220.

132. Baker, M. (2009) iPS cells make mice that make mice. Nat. Rep. Stem Cells, doi:10.1038/stemcells.2009.106.

133. Guo, J., Baojiang, W., Shuyu, L., Siqin, B., Lixia, Z., Shuxiang, H., Wei, S., Jie, S., Yangfeng, D. and Xihe, L. (2014) Contribution of mouse embryonic stem cells and induced pluripotent stem cells to chimeras through injection and co-culture of embryos. Stem Cell Int., 2014: Article ID: 409021, 1-9. 